\title{
Optimal production strategy for deteriorating items with varying demand pattern under inflation
}

\author{
Ibraheem Abdul $^{\mathrm{a}^{*}}$ and Atsuo Murata ${ }^{\mathrm{a}}$
}

\begin{abstract}
${ }^{a}$ Department of Intelligent Mechanical Systems Engineering, Graduate School of Natural Science and Technology, Okayama University, 3-1-1, Tsushimanaka, Okayama 700-8530, Japan.

\begin{tabular}{|c|c|}
\hline AR T I C L E I N F O & A B S T RAC T \\
\hline $\begin{array}{l}\text { Article history: } \\
\text { Received } 28 \text { January } 2011 \\
\text { Received in revised form } \\
\text { April, } 12,2011 \\
\text { Accepted } 13 \text { April } 2011 \\
\text { Available online } \\
\text { 14 April 2011 } \\
\text { Keywords: } \\
\text { Production } \\
\text { Inventory } \\
\text { Varying demand pattern } \\
\text { Weibull deterioration } \\
\text { Partial backlogging } \\
\text { Inflation }\end{array}$ & $\begin{array}{l}\text { This paper presents production-inventory models for deteriorating items with increasing-steady- } \\
\text { decreasing demand pattern under the effect of inflation and time value of money. This type of } \\
\text { demand behavior can be observed in some fashion products or seasonal products in general. } \\
\text { Shortages are allowed with partial backlogging of demand and a two-parameter Weibull- } \\
\text { distribution function is used for the deterioration of items in order to make the models more } \\
\text { generalized and realistic. The models generate optimal values of initial production run time, } \\
\text { onset of shortages, production recommencement time, and total production quantity that } \\
\text { minimizes the total relevant costs of production and inventory for any given set of system } \\
\text { parameters. Various possible production strategies available for items with variable demand } \\
\text { pattern are examined to determine the optimal production strategy. The discounted cash flow } \\
\text { approach and trust region optimization methods are used to obtain the optimal results. The } \\
\text { Numerical examples and sensitivity analysis show that the optimal production strategy may } \\
\text { vary with changes in system parameters. }\end{array}$ \\
\hline
\end{tabular}
\end{abstract}

\section{Introduction}

The classical economic production quantity (EPQ) model assumes constant demand and infinite lifetime of items in inventory. Subsequent research efforts have led to the removal of these two restrictions in consideration of time varying demand functions and finite lifetimes for inventoried items. This is in line with common experience in day-to-day production and inventory management. The time-varying demand functions considered in most EPQ models are unidirectional, i.e. they are either continuously non-decreasing or continuously non-increasing function of time. This paper, however, focuses on products whose demand variation is a mixture of non-decreasing, constant and non-increasing functions of time. This type of demand behavior can be observed in some seasonal items such as fruits, fish, winter cosmetics, fashion apparels, etc. The demand for this class of items increases with time at the beginning of its season. It attains a peak and becomes steady at the middle of the season and it finally decreases when the time reaches to the end of the season. Unlike products

\footnotetext{
* Corresponding author. Tel.: +81-90-6418-0253; fax: +81-86-251-8056

E-mail: dotun.abdul@gmail.com (I. Abdul)

(c) 2011 Growing Science Ltd. All rights reserved.

doi: $10.5267 / j$.ijiec.2011.04.002
} 
with unidirectional demand pattern, various strategies can be adopted in the production of this type of goods.

The Economic Order Quantity (EOQ) model developed by Harris in 1915 was popularized by Wilson in 1934 (Hariga, 1995), while Taft introduced the Economic Production Quantity (EPQ) model in 1918. Ghare and Shrader (1963) was the first to extend the classical EOQ formula to include exponential decay, wherein a constant fraction of on hand inventory is assumed lost due to deterioration. Misra (1975) developed the first production lot size model in which both constant and variable rate of deterioration were considered (Raafat, 1991). In subsequent models, the deterioration rates of the items vary from exponential distribution to gamma, normal or Weibull distributions. According to Nahmias (1982), the exponential decay can be derived by assuming that a constant fraction of on-hand stock is lost (i.e. deteriorates) each period regardless of the age distribution of inventory. Hence, those models with exponential deterioration rate are classified as having constant deterioration rate while those with Weibull, normal or other distribution are considered as having variable rate of deterioration (Urban 2005). There are also different Production-inventory models with constant deterioration rate (Maity \& Maiti, 2005; Hedjar et al., 2004; Yang \& Wee, 2003; Yu, 2007; Alfares et al., 2005; Jaggi et al., 2011). A generalized model in which deterioration and production varies continuously with time was developed by Balkhi (2001) while Lo et al. (2007) developed an integrated production inventory model with varying rate of deterioration, imperfect production processes and inflation. Other models with varying deterioration rate include Pal et al., (2008) and Sridevi et al. (2010).

Allowing shortages in the demand of an inventoried item is one of the extensions to make the classical EPQ model suit day-to-day inventory situations. Researchers usually assume complete or partial backlogging of demand during shortages. Many researchers assume partial backlogging of demand, which is more realistic in real life inventory situations. One way of considering partial backlogging is to assume that a constant fraction of demand during shortages is backlogged. This is the method adopted by Goyal and Giri (2003), Jolai et al. (2006), Lo et al. (2007), Taleizadeh et al. (2010), and others. Yang (2005) proposed that in many real-life situations, especially for fashionable commodities and seasonal products, the willingness of a customer to wait for backlogging during a shortage period is declining with the length of the waiting time. The longer the waiting time is, the smaller the backlogging rate would be. Papachristos and Skouri (2000), Ouyang et al. (2006), Abad (2003), Lin and Lin (2006), Yang (2005), Chang et al. (2006), Chern et al. (2008), etc. assumed that the fraction of shortages backordered is a decreasing and differentiable function of the waiting time up to the next replenishment.

Consideration of the effects of time value of money and inflation is another important extension that makes recent inventory models applicable to real-life inventory problems. Researchers have approached this in two major ways, one of which is to minimize the present worth (PW) of total inventory costs over the time horizon after incorporating appropriate discounting factors in all relevant cost values. This was the approach adopted by Chung and Tsai (2001), Shah (2006), Chang et al. (2002), Moon et al. (2005), Hou (2006), Jolai et al. (2006), Chern et al. (2008) etc. Another approach is to maximize the total net present-value (NPV) of profit for the time horizon after considering the present-value of profits from sales and present-value of all relevant cost components and this method was used by Wee and Law (2001), Dey et al. (2008).

All the above models considered demand as either constant or single continuously non-decreasing / non-increasing function of time and may not be suitable for products whose demand variation is a mixture of non-decreasing, constant and non-increasing functions of time. Hill (1995) developed the first model that addresses this type of demand behavior. He proposed a time dependent demand pattern that is a combination of two different types of demand in two successive periods over the entire time horizon and termed it as ramp-type demand pattern. This pattern is quite different from the usual unidirectional time dependent demand patterns mentioned earlier. Mandal and Pal (1998) investigated an order-level inventory model for deteriorating items where the demand rate is a ramptype function of time. $\mathrm{Wu}$ (2001) observed that this type of demand pattern is generally seen in the case of new brand of consumer goods coming to the market. The demand rate for such items 
increases with time up to certain time and then ultimately stabilizes and becomes constant. The works of Panda et al. (2009b), Cheng and Wang (2009), Mahata and Goswami (2009) and Abdul and Murata (2011) are examples of recent EOQ models with ramp-type demand.

So far, only few researchers considered the production-inventory problem for deteriorating items with ramp-type demand pattern. Manna and Chaudhuri (2006) developed a production-inventory model for deteriorating items with ramp-type demand pattern. The demand pattern was a two-phase ramptype function modeled by a linear function of time in the first phase and a constant in the second phase. Panda et al. (2009a) developed a single item economic production quantity (EPQ) model with ramp-type demand function. The model determines the optimal production stopping time to maximize total unit profit of the system. Recently, Manna and Chiang (2010) extended the EPQ model of Manna and Chaudhuri (2006) to cover items with Weibull-distribution deterioration. These EPQ models with ramp-type demand considered only the growth and the steady phases of demand for a deteriorating item. Hence, they are not suitable for items with increasing-steady-decreasing demand pattern described earlier.

This paper presents production-inventory models that consider the growth, the steady and the decline phases of demand for deteriorating items having increasing-steady-decreasing demand pattern. The models use a general ramp-type demand function that allows three-phase variation in demand pattern. This pattern represents the various phases of demand commonly observed in many products in the market. A two-parameter Weibull-distribution function is used for the deterioration of items in order to make the model more generalized and realistic. Shortages are allowed with partial backlogging of demand and the effects of inflation and time value of money are incorporated into developing the model. We examine various possible production strategies available for items having demand pattern variation and use the discounted cash flow approach and trust region optimization methods to obtain the optimal production strategy. The paper is organized as follows: Section 1 contains an introduction and literature review. The assumptions and notations used in developing the models are presented in Section 2 while the proposed models are presented in Section 3. Section 4 deals with the optimal solution procedure while numerical examples and conclusions are presented in Sections 5 and 6 , respectively.

\section{Assumptions and notations}

The following assumptions and notations are used in formulating the models:

1. The production-inventory cycle consists a single period, of length $T$.

2. Deterioration rate is represented by a two-parameter Weibull-distribution function $\theta(t)=a b t^{b-1}$.

3. Production rate, $K(t)=\alpha f(t)$, is a known function of demand rate $(\alpha>1)$.

4. Shortages are allowed and partially backlogged and fraction of demand backlogged is $\beta ;(0 \leq \beta \leq 1)$.

5. No repair or replacement of deteriorated items during the period under review is allowed.

6. $i$ is the inflation rate.

7. $r$ is the discount rate representing time value of money.

8. $R(=r-i)$ represents the discount rate net of inflation.

9. Set up cost per cycle $\left(A_{S}\right)$, production cost per unit $\left(C_{P}\right)$, shortage cost per unit $\left(C_{S H}\right)$, inventory holding cost per unit $\left(C_{H}\right)$, are known and constant during the cycle.

10. Demand rate $f(t)$ is a general time dependent ramp-type function, and is of the form:

$$
\begin{aligned}
& f(t)=\left\{\begin{array}{l}
g(t), 0 \leq t \leq \mu, \\
g(\mu), \quad \mu \leq t \leq \gamma, \\
h(t), t \geq \gamma .
\end{array}\right. \\
& g(t) \geq 0, h(t) \geq 0,0 \leq \mu \leq \gamma, g(\mu)=h(\gamma) .
\end{aligned}
$$

The function $g(t)$ can be any continuous, non-decreasing function of time, while $h(t)$ is any continuous, non-increasing function of time in the given interval. Parameters ' $\mu$ ' and ' $\gamma$ ' represent the trend of the ramp-type demand function. 


\section{Model formulation}

The system consists of a single production-inventory cycle whose period begins with zero inventories. Production commences at time $t=0$, and inventory level rises continuously up to time $t=$ $t_{1}$ after meeting the requirement of demand and deterioration. Production stops at time $t=t_{1}$ and consumption brings the inventory level to zero at the time $t=t_{2}$. Shortages occur from time $t=t_{2}$ to time $t=t_{3}$ after which production commences again up to time $t=T$, in order to clear the backlog. Three different scenarios may arise during the cycle according to the demand pattern exhibited by the item during the period. These scenarios are examined below:

\section{Scenario I:}

In this scenario, production commences at time $t=0$ and stops while the demand is increasing at time $t=t_{1}$. Consumption follows till the inventory drops to zero and shortage commences. The onset of shortages can occur while demand is increasing, constant or decreasing. This leads to three different cases, which are considered in Cases I - III below.

\section{Scenario II:}

In this scenario production stops while the demand is constant and consumption continues till the inventory drops to zero. The onset of shortages can occur while demand is constant or decreasing. This gives rise to two different cases analyzed in Case IV and Case V below.

\section{Scenario III:}

Production continues from time $t=0$ till such a time when the demand for the item declines (i.e. $t_{1}>\gamma$ ). The onset of shortages can only be while demand is decreasing and it is examined in Case VI below. Each of the Cases described above constitute a Production Strategy. The objective is to determine the optimal values of initial production run time $t_{1}^{*}$, onset of shortages $t_{2}^{*}$, production recommencement time $t_{3}^{*}$, and total production quantity $Q^{*}$ that minimizes total relevant costs of production and inventory for each strategy and ultimately the optimal production strategy.

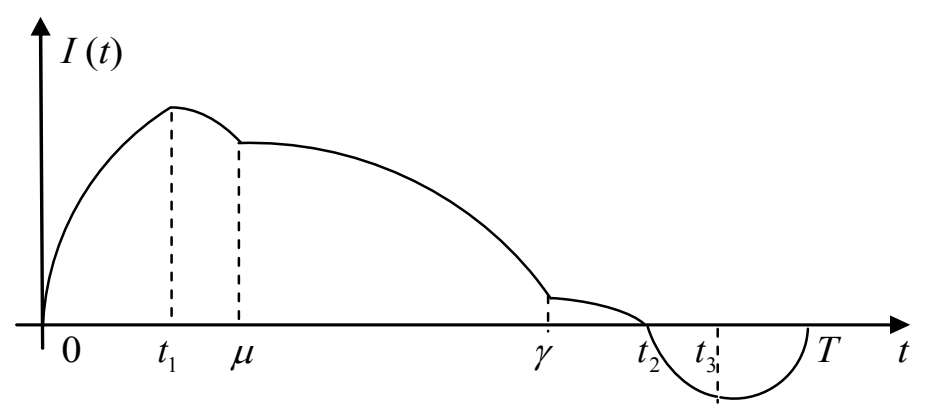

Fig. 1. Variation of inventory level with time for Case I

\subsection{Case I: Production stops while demand is increasing and Stock is depleted when demand is decreasing (i.e. $t_{1}<\mu, t_{2}>\gamma$ )}

The variation of the inventory level, $I(t)$, with time $t$ for the cycle is as shown in Fig. 1. Production rate for this model is always greater than the demand rate. The behavior of the production-inventory system at different phases is described below with the appropriate differential equations:

Production begins at $t=0$ and stops at $t=t_{1}$, within the interval consumption due to demand and deterioration also takes place. The rate of change of inventory level, $I_{A}(t)$, with time is as follows:

$$
\frac{d I_{A}(t)}{d t}=K(t)-g(t)-\theta(t) I_{A}(t), 0 \leq t \leq t_{1} ;\left(I_{A}(0)=0\right) \text {. }
$$


In the interval $\left[t_{1}, \mu\right]$, production ceases and consumption continues to reduce the level of accumulated inventory. If the inventory level during this interval is represented by $I_{B}(t)$, its variation with time is as follows:

$$
\frac{d I_{B}(t)}{d t}=-g(t)-\theta(t) I_{B}(t) ; t_{1} \leq t \leq \mu ;\left\{I_{B}(\mu)=I_{C}(\mu)\right\} \text {. }
$$

Demand becomes steady during the interval $[\mu, \gamma]$, while demand and deterioration continue to reduce inventory level. The rate of change of the inventory level, $I_{C}(t)$, with time is as follows:

$$
\frac{d I_{C}(t)}{d t}=-g(\mu)-\theta(t) I_{C}(t), \mu \leq t \leq \gamma ;\left\{I_{C}(\gamma)=I_{D}(\gamma)\right\}
$$

When $\gamma \leq t \leq t_{2}$, the demand declines and the level of inventory tends to zero at time $t=t_{2}$ due to consumption through demand and deterioration. Variation of inventory level, $I_{D}(t)$, with time is as follows:

$$
\frac{d I_{D}(t)}{d t}=-h(t)-\theta(t) I_{D}(t), \gamma \leq t \leq t_{2} ;\left\{I_{D}\left(t_{2}\right)=0\right\} \text {. }
$$

Shortages occur from time $t=t_{2}$ to time $t=t_{3}$ after which production is commenced to clear the backlog. The cycle ends at time $t=T$. Variation of the inventory level with time is as follows:

$$
\begin{array}{ll}
\frac{d I_{E}(t)}{d t}=-\beta h(t), & t_{2} \leq t \leq t_{3}, I_{E}\left(t_{2}\right)=0, \\
\frac{d I_{F}(t)}{d t}=K(t)-h(t), \quad t_{3} \leq t \leq T, I_{F}(T)=0 .
\end{array}
$$

The solutions of Eq. (1) to Eq. (5) above are as follows:

$$
\begin{aligned}
& I_{A}(t)=e^{-a t^{b}} \int_{0}^{t} e^{a x^{b}}(K(x)-g(x)) d x, \\
& I_{B}(t)=e^{-a t^{b}}\left(\int_{t}^{\mu} e^{a x^{b}} g(x) d x+\int_{\mu}^{\gamma} e^{a x^{b}} g(\mu) d x+\int_{\gamma}^{t_{2}} e^{a x^{b}} h(x) d x\right), \\
& I_{C}(t)=e^{-a t^{b}}\left(\int_{t}^{\gamma} e^{a x^{b}} g(\mu) d x+\int_{\gamma}^{t_{2}} e^{a x^{b}} h(x) d x\right), \\
& I_{D}(t)=e^{-a t^{b}}\left(\int_{t}^{t_{2}} e^{a x^{b}} h(x) d x\right), \\
& I_{E}(t)=\int_{t}^{t_{2}} \beta h(x) d x, \\
& I_{F}(t)=\int_{T}^{t}(K(x)-h(x)) d x .
\end{aligned}
$$

The present worth of inventory holding cost is as follows:

$$
P W H C=C_{H}\left(\int_{0}^{t_{1}} I_{A}(t) e^{-R t} d t+\int_{t_{1}}^{\mu} I_{B}(t) e^{-R t} d t+\int_{\mu}^{\gamma} I_{C}(t) e^{-R t} d t+\int_{\gamma}^{t_{2}} I_{D}(t) e^{-R t} d t\right) .
$$

The present worth of shortage cost is as follows:

$$
P W S H C=-C_{S H}\left(\int_{t_{2}}^{t_{3}} I_{E}(t) e^{-R t} d t+\int_{t_{3}}^{T} I_{F}(t) e^{-R t} d t\right) .
$$

The present worth of loss cost is as follows:

$$
P W L C=(1-\beta) C_{L}\left(\int_{t_{2}}^{t_{3}} h(t) e^{-R t} d t\right) \text {. }
$$

The present worth of production cost is as follows: 


$$
P W P R C=C_{P}\left(\int_{0}^{t_{1}} K(t) e^{-R t} d t+\int_{t_{3}}^{T} K(t) e^{-R t} d t\right) .
$$

The present worth of set-up cost is as follows:

$$
P W S U C=A_{S}+A_{S} e^{-R t_{3}} \text {. }
$$

Total relevant cost is as follows:

$$
T C_{1}\left(t_{1}, t_{2}, t_{3}\right)=P W H C+P W S H C+P W L C+P W P R C+P W S U C .
$$

The inventory levels at time $t=t_{1}$ must be equal and likewise the inventory level at time $t=t_{3}$. Hence the following constraints apply to the system.

$$
\begin{aligned}
& \text { I. } I_{A}\left(t_{1}\right)=I_{B}\left(t_{1}\right), \\
& \text { II. } I_{E}\left(t_{3}\right)=I_{F}\left(t_{3}\right), \\
& \text { III. } 0<t_{1}<\mu<\gamma<t_{2}<t_{3}<T .
\end{aligned}
$$

The objective is to determine the optimal values of the production run time $t_{1}^{*}$, the onset of shortages $t_{2}^{*}$, and the production re-commencement time $t_{3}^{*}$ for the cycle. This is achieved by minimizing the total relevant cost $T C_{1}\left(t_{1}, t_{2}, t_{3}\right)$ subject to the constraints.

\subsection{Case II: Production stops while demand is increasing and Stock is depleted when demand is} steady (i.e. $t_{1}<\mu, \mu \leq t_{2} \leq \gamma$ )

The behavior of the production-inventory system in the interval $[0, \mu]$ is the same as that of Case I and the equations are as follows:

$$
\begin{aligned}
& \frac{d I_{A}(t)}{d t}=K-g(t)-\theta(t) I_{A}(t), 0 \leq t \leq t_{1} ;\left(I_{A}(0)=0\right), \\
& \frac{d I_{B}(t)}{d t}=-g(t)-\theta(t) I_{B}(t), t_{1} \leq t \leq \mu ;\left\{I_{B}(\gamma)=I_{C}(\gamma)\right\} .
\end{aligned}
$$

When $\mu \leq t \leq t_{2}$, demand becomes steady at $t=\mu$, while consumption continues till the level of inventory drop to zero at time $t=t_{2}$. The rate of change of the inventory level, $I_{C}(t)$, with time is as follows:

$$
\frac{d I_{C}(t)}{d t}=g(\mu)-\theta(t) I_{C}(t), \mu \leq t \leq t_{2} ;\left\{I_{C}\left(t_{2}\right)=0\right\}
$$

In the interval $\left[t_{2}, t_{3}\right]$, shortages occur with partial backlogging of demand while demand changes from steady to declining pattern at time $t=\gamma$ within this interval. Variation of inventory level with time during this interval is as follows:

$$
\begin{aligned}
& \frac{d I_{D}(t)}{d t}=-\beta g(\mu), t_{2}<t \leq \gamma ;\left\{I_{D}\left(t_{2}\right)=0\right\}, \\
& \frac{d I_{E}(t)}{d t}=-\beta h(t), \quad \gamma \leq t \leq t_{3}, I_{D}(\gamma)=I_{E}(\gamma) .
\end{aligned}
$$

At $t_{3} \leq t \leq T$, production is commenced to clear the backlog and the cycle ends at time $t=T$. The rate of change of the inventory level, $I_{F}(t)$, with time is as follows:

$$
\frac{d I_{F}(t)}{d t}=K(t)-h(t), t_{3}<t \leq T, I_{F}(T)=0 .
$$

The solutions of Eq. (14) to Eq. (18) above are as follows: 


$$
\begin{aligned}
& I_{A}(t)=e^{-a t^{b}} \int_{0}^{t} e^{a x^{b}}(K(x)-g(x)) d x, \\
& I_{B}(t)=e^{-a t^{b}}\left(\int_{\mu}^{t_{2}} e^{a x^{b}} g(\mu) d x+\int_{t}^{\mu} e^{a x^{b}} g(x) d x\right), \\
& I_{C}(t)=e^{-a t^{b}}\left(\int_{t}^{t_{2}} e^{a x^{b}} g(\mu) d x\right), \\
& I_{D}(t)=\int_{t}^{t_{2}} \beta g(\mu) d x, \\
& I_{E}(t)=\int_{t}^{\gamma} \beta h(x) d x+\int_{\gamma}^{t_{2}} \beta g(\mu) d x, \\
& I_{F}(t)=\int_{T}^{t}(K(x)-h(x)) d x .
\end{aligned}
$$

The present worth of inventory holding cost is as follows:

$$
P W H C=C_{H}\left(\int_{0}^{t_{1}} I_{A}(t) e^{-R t} d t+\int_{t_{1}}^{\mu} I_{B}(t) e^{-R t} d t+\int_{\mu}^{t_{2}} I_{C}(t) e^{-R t} d t\right) .
$$

The present worth of shortage cost is as follows:

$$
P W S H C=-C_{S H}\left(\int_{t_{2}}^{\gamma} I_{D}(t) e^{-R t} d t+\int_{\gamma}^{t_{3}} I_{E}(t) e^{-R t} d t+\int_{t_{3}}^{T} I_{F}(t) e^{-R t} d t\right) .
$$

The present worth of loss cost is as follows:

$$
P W L C=(1-\beta) C_{L}\left(\int_{t_{2}}^{\gamma} g(\mu) e^{-R t} d t+\int_{\gamma}^{t_{3}} h(t) e^{-R t} d t\right) .
$$

The present worth of production cost is as follows:

$$
P W P R C=C_{P}\left(\int_{0}^{t_{1}} K(t) e^{-R t} d t+\int_{t_{3}}^{T} K(t) e^{-R t} d t\right) .
$$

The present worth of set-up cost is as follows:

$$
P W S U C=A_{S}+A_{S} e^{-R t_{3}} \text {. }
$$

Total relevant cost is as follows:

$$
T C_{2}\left(t_{1}, t_{2}, t_{3}\right)=P W H C+P W S H C+P W L C+P W P R C+P W S U C .
$$

The following constraints apply to the system for the same reason as given in Case I.
I. $I_{A}\left(t_{1}\right)=I_{B}\left(t_{1}\right)$,
II. $I_{E}\left(t_{3}\right)=I_{F}\left(t_{3}\right), \quad$ III. $0<t_{1}<\mu<t_{2}<\gamma<t_{3}<T$.

The objective is to determine the optimal values of $t_{1}^{*}, t_{2}^{*}, t_{3}^{*}$, by minimizing the total variable cost $T C_{2}\left(t_{1}, t_{2}, t_{3}\right)$ subject to constraints.

3.3 Case III: Production stops while demand is increasing and Stock depleted when demand is increasing (i.e. $t_{1}<\mu, t_{2}<\mu$ )

Production begins at $\mathrm{t}=0$ and stops at $\mathrm{t}=t_{1}$, the rate of change of inventory level with time, $I_{A}(t)$ is as follows:

$$
\frac{d I_{A}(t)}{d t}=K-g(t)-\theta(t) I_{A}(t), 0 \leq t \leq t_{1} ;\left(I_{A}(0)=0\right) \text {. }
$$

Consumption due to demand and deterioration reduce the level of accumulated inventory to zero shortly after the time $t=t_{2}$. If the inventory level during this interval is represented by $I_{B}(t)$, its variation with time is as follows:

$$
\frac{d I_{B}(t)}{d t}=-g(t)-\theta(t) I_{B}(t), t_{1} \leq t \leq \mu ;\left\{I_{B}\left(t_{2}\right)=0\right\} \text {. }
$$

In the interval $\left[t_{2}, t_{3}\right]$, shortages occur with partial backlogging of demand while demand pattern undergoes changes from $g(t)$ to $g(\mu)$ at time $t=\mu$ and later declines at $t=\gamma$ within the interval. Variation of inventory level with time during this interval is as follows: 


$$
\begin{aligned}
& \frac{d I_{C}(t)}{d t}=-\beta g(t), t_{2}<t \leq \mu\left\{I_{C}\left(t_{2}\right)=0\right\}, \\
& \frac{d I_{D}(t)}{d t}=-\beta g(\mu), \mu<t \leq \gamma ;\left\{I_{C}(\mu)=I_{D}(\mu)\right\}, \\
& \frac{d I_{E}(t)}{d t}=-\beta h(t), \quad \gamma \leq t \leq t_{3} ;\left\{I_{D}(\gamma)=I_{E}(\gamma)\right\} .
\end{aligned}
$$

At $t_{3} \leq t \leq T$, production is commenced to clear the backlog and the cycle ends at time $t=T$. The rate of change of the inventory level, $I_{F}(t)$, with time in this case, is as follows:

$$
\frac{d I_{F}(t)}{d t}=K(t)-h(t), t_{3}<t \leq T, I_{F}(T)=0 .
$$

The solutions of Eq. (26) to Eq. (29) above are as follows:

$$
\begin{aligned}
& I_{A}(t)=e^{-a t^{b}} \int_{0}^{t} e^{a x^{b}}(K(x)-g(x)) d x, \\
& I_{B}(t)=e^{-a t^{b}}\left(\int_{t}^{t_{2}} e^{a x^{b}} g(x) d x\right), \\
& I_{C}(t)=\int_{t}^{t_{2}} \beta g(x) d x, \\
& I_{D}(t)=\int_{t}^{\mu} \beta g(\mu) d x+\int_{\mu}^{t_{2}} \beta g(x) d x, \\
& I_{E}(t)=\int_{t}^{\gamma} \beta h(x) d x+\int_{\gamma}^{\mu} \beta g(\mu) d t+\int_{\mu}^{t_{2}} \beta g(x) d x, \\
& I_{F}(t)=\int_{T}^{t}(K(x)-h(x)) d x ; t_{3} \leq t \leq T .
\end{aligned}
$$

The present worth of inventory holding cost, shortage cost, loss cost, production cost, and set-up cost are as follows:

$$
\begin{aligned}
& P W H C=C_{H}\left(\int_{0}^{t_{1}} I_{A}(t) e^{-R t} d t+\int_{t_{1}}^{t_{2}} I_{B}(t) e^{-R t} d t\right), \\
& P W S H C=-C_{S H}\left(\int_{t_{2}}^{\mu} I_{C}(t) e^{-R t} d t+\int_{\mu}^{\gamma} I_{D}(t) e^{-R t} d t+\int_{\gamma}^{t_{3}} I_{E}(t) e^{-R t} d t+\int_{t_{3}}^{T} I_{F}(t) e^{-R t} d t\right), \\
& P W L C=(1-\beta) C_{L}\left(\int_{t_{2}}^{\mu} g(t) e^{-R t} d t+\int_{\mu}^{\gamma} g(\mu) e^{-R t} d t+\int_{\gamma}^{t_{3}} h(t) e^{-R t} d t\right), \\
& P W P R C=C_{P}\left(\int_{0}^{t_{1}} K(t) e^{-R t} d t+\int_{t_{3}}^{T} K(t) e^{-R t} d t\right), \\
& P W S U C=A_{S}+A_{S} e^{-R t_{3}} .
\end{aligned}
$$

Total relevant cost is as follows:

$$
T C_{3}\left(t_{1}, t_{2}, t_{3}\right)=P W H C+P W S H C+P W L C+P W P R C+P W S U C .
$$

The following constraints apply to the system:

$$
\text { I. } I_{A}\left(t_{1}\right)=I_{B}\left(t_{1}\right) \text {, II. } I_{E}\left(t_{3}\right)=I_{F}\left(t_{3}\right), \text { III. } 0<t_{1}<t_{2}<\mu<\gamma<t_{3}<T \text {. }
$$

The objective is to determine the optimal values of $t_{1}^{*}, t_{2}^{*}, t_{3}^{*}$, by minimizing the total variable cost $T C_{3}\left(t_{1}, t_{2}, t_{3}\right)$ subject to the constraints.

3.4 Case IV: Production stops while demand is steady and Stock is depleted when demand is steady (i.e. $\mu \leq t_{1} \leq \gamma, \mu \leq t_{2} \leq \gamma$ )

In this case, the cycle begins with production and the accumulated inventory gets depleted gradually due to demand and deterioration. Production stops at time $t_{1}\left(\mu \leq t_{1} \leq \gamma\right)$ and shortages commences 
soon afterwards at time $t_{2}\left(\mu \leq t_{2} \leq \gamma\right)$. The demand pattern changes from $g(t)$ to $g(\mu)$ before the stoppage of production and later from $g(\mu)$ to $h(t)$ after the commencement of shortages.The equations of the system are as follows:

$$
\begin{aligned}
& \frac{d I_{A}(t)}{d t}=K(t)-g(t)-\theta I_{A}(t), 0 \leq t \leq t_{1} ;\left\{I_{A}(0)=0\right\}, \\
& \frac{d I_{B}(t)}{d t}=K(t)-g(\mu)-\theta I_{B}(t) ; t_{1} \leq t \leq \mu ;\left\{I_{A}(\mu)=I_{B}(\mu)\right\}, \\
& \frac{d I_{C}(t)}{d t}=-g(\mu)-\theta I_{C}(t), \mu \leq t \leq t_{2} ;\left\{I_{C}\left(t_{2}\right)=0\right\}, \\
& \frac{d I_{D}(t)}{d t}=-\beta g(\mu), t_{2}<t \leq \gamma ;\left\{I_{D}\left(t_{2}\right)=0\right\}, \\
& \frac{d I_{E}(t)}{d t}=-\beta h(t), \quad \gamma \leq t \leq t_{3}, I_{D}(\gamma)=I_{E}(\gamma), \\
& \frac{d I_{F}(t)}{d t}=K(t)-h(t), \quad t_{3}<t \leq T, I_{F}(T)=0 .
\end{aligned}
$$

The solutions of Eq. (33) above are as follows:

$$
\begin{aligned}
& I_{A}(t)=e^{-a t^{b}} \int_{0}^{t} e^{a x^{b}}(K(x)-g(x)) d x, \\
& I_{B}(t)=e^{-a t^{b}}\left(\int_{0}^{\mu} e^{a x^{b}}(K(x)-g(x)) d x+\int_{\mu}^{t} e^{a x^{b}}(K(x)-g(\mu)) d x\right), \\
& I_{C}(t)=e^{-a t^{b}}\left(\int_{t}^{t_{2}} e^{a x^{b}} g(\mu) d x\right), \\
& I_{D}(t)=\int_{t}^{t_{2}} \beta g(\mu) d x, \\
& I_{E}(t)=\int_{t}^{\gamma} \beta h(x) d x+\int_{\gamma}^{t_{2}} \beta g(\mu) d x, \\
& I_{F}(t)=\int_{T}^{t}(K(x)-h(x)) d x .
\end{aligned}
$$

The present worth of inventory holding cost, shortage cost, loss cost, production cost, and set-up cost are as follows:

$$
\begin{aligned}
& P W H C=C_{H}\left(\int_{0}^{\mu} I_{A}(t) e^{-R t} d t+\int_{\mu}^{t_{1}} I_{B}(t) e^{-R t} d t+\int_{t_{1}}^{t_{2}} I_{C}(t) e^{-R t} d t\right), \\
& P W S H C=-C_{S H}\left(\int_{t_{2}}^{\gamma} I_{D}(t) e^{-R t} d t+\int_{\gamma}^{t_{3}} I_{E}(t) e^{-R t} d t+\int_{t_{3}}^{T} I_{F}(t) e^{-R t} d t\right), \\
& P W L C=(1-\beta) C_{L}\left(\int_{t_{2}}^{\gamma} g(\mu) e^{-R t} d t+\int_{\gamma}^{t_{3}} h(t) e^{-R t} d t\right), \\
& P W P R C=C_{P}\left(\int_{0}^{\mu} K(t) e^{-R t} d t+\int_{\mu}^{t_{1}} K(t) e^{-R t} d t+\int_{t_{3}}^{T} K(t) e^{-R t} d t\right), \\
& P W S U C=A_{S}+A_{S} e^{-R t_{3}} .
\end{aligned}
$$

Total relevant cost is as follows:

$$
T C_{4}\left(t_{1}, t_{2}, t_{3}\right)=P W H C+P W S H C+P W L C+P W P R C+P W S U C .
$$

The following constraints apply to the system.
I. $I_{B}\left(t_{1}\right)=I_{C}\left(t_{1}\right)$,
II. $I_{E}\left(t_{3}\right)=I_{F}\left(t_{3}\right)$,
III. $0<\mu<t_{1}<t_{2}<\gamma<t_{3}<T$.

The optimal production schedules in this case can be obtained by minimizing $T C_{4}\left(t_{1}, t_{2}, t_{3}\right)$ subject to the constraints stated above. 
3.5 Case V: Production stops while demand is steady and Stock is depleted when demand is decreasing, (i.e. $\mu \leq t_{1} \leq \gamma, t_{2}>\gamma$ )

The behavior of the system in this case is similar to Case IV above, except that, in this case the inventory is brought to zero while the demand is decreasing (i.e. $\mu \leq t_{1} \leq \gamma, t_{2}>\gamma$ ). The demand pattern changes from $g(t)$ to $g(\mu)$ before the stoppage of production and from $g(\mu)$ to $h(t)$ before the commencement of shortages. The equations of the system and the solutions are given in Eq. (37) and Eq. (38) respectively.

$$
\begin{aligned}
& \frac{d I_{A}(t)}{d t}=K(t)-g(t)-\theta I_{A}(t), 0 \leq t \leq \mu ;\left\{I_{A}(0)=0\right\}, \\
& \frac{d I_{B}(t)}{d t}=K(t)-g(\mu)-\theta I_{B}(t) ; \mu \leq t \leq t_{1} ;\left\{I_{B}(\mu)=I_{A}(\mu)\right\}, \\
& \frac{d I_{C}(t)}{d t}=-g(\mu)-\theta I_{C}(t), t_{1} \leq t \leq \gamma ;\left\{I_{C}(\gamma)=I_{D}(\gamma)\right\}, \\
& \frac{d I_{D}(t)}{d t}=-h(t)-\theta I_{D}(t), \gamma<t \leq t_{2} ;\left\{I_{D}\left(t_{2}\right)=0\right\}, \\
& \frac{d I_{E}(t)}{d t}=-\beta h(t), \quad t_{2} \leq t \leq t_{3},\left\{I_{E}\left(t_{2}\right)=0\right\}, \\
& \frac{d I_{F}(t)}{d t}=K(t)-h(t), t_{3}<t \leq T,\left\{I_{F}(T)=0\right\} . \\
& I_{A}(t)=e^{-a t^{b}} \int_{0}^{t} e^{a x^{b}}(K(x)-g(x)) d x, \\
& I_{B}(t)=e^{-a t^{b}}\left(\int_{\mu}^{t} e^{a x^{b}}(K(x)-g(\mu)) d x+\int_{0}^{\mu} e^{a x^{b}}(K(x)-g(x)) d x\right), \\
& I_{C}(t)=e^{-a t^{b}}\left(\int_{t}^{\gamma} e^{a x^{b}} g(\mu) d x+\int_{\gamma}^{t_{2}} e^{a x^{b}} h(x) d x\right), \\
& I_{D}(t)=e^{-a t^{b}} \int_{t}^{t_{2}} e^{a x^{b}} h(x) d x, \\
& I_{E}(t)=-\int_{t_{2}}^{t} \beta h(x) d x, \\
& I_{F}(t)=-\int_{t}^{T}(K(x)-h(x)) d x .
\end{aligned}
$$

The present worth of inventory holding cost, shortage cost, loss cost, production cost, and set-up cost are as follows:

$$
\begin{aligned}
& P W H C=C_{H}\left(\int_{0}^{\mu} I_{A}(t) e^{-R t} d t+\int_{\mu}^{t_{1}} I_{B}(t) e^{-R t} d t+\int_{t_{1}}^{\gamma} I_{C}(t) e^{-R t} d t+\int_{\gamma}^{t_{2}} I_{D}(t) e^{-R t} d t\right), \\
& P W S H C=-C_{S H}\left(\int_{t_{2}}^{t_{3}} I_{E}(t) e^{-R t} d t+\int_{t_{3}}^{T} I_{F}(t) e^{-R t} d t\right), \\
& P W L C=(1-\beta) C_{L}\left(\int_{t_{2}}^{t_{3}} h(t) e^{-R t} d t\right), \\
& P W P R C=C_{P}\left(\int_{0}^{\mu} K(t) e^{-R t} d t+\int_{\mu}^{t_{1}} K(t) e^{-R t} d t+\int_{t_{3}}^{T} K(t) e^{-R t} d t\right), \\
& P W S U C=A_{S}+A_{S} e^{-R t_{3}} .
\end{aligned}
$$

Total relevant cost is as follows:

$$
T C_{5}\left(t_{1}, t_{2}, t_{3}\right)=P W H C+P W S H C+P W L C+P W P R C+P W S U C .
$$


The optimal production schedules can be obtained by minimizing $T C_{5}\left(t_{1}, t_{2}, t_{3}\right)$ subject to the constraints below.

I. $I_{B}\left(t_{1}\right)=I_{C}\left(t_{1}\right), \quad$ II. $I_{E}\left(t_{3}\right)=I_{F}\left(t_{3}\right), \quad$ III. $0<\mu<t_{1}<\mu<t_{2}<t_{3}<T$.

3.6 Case VI: Production stops while demand is decreasing and Stock is depleted when demand is decreasing, (i.e. $t_{1}>\gamma, t_{2}>\gamma$ )

The cycle begins with production and it continues till a time $t_{1}\left(t_{1}>\gamma\right)$ when it is stopped. Inventory is brought to zero at time $t_{2}\left(t_{2}>\gamma\right)$ while the demand rate is $h(t)$. Shortage follows and the cycle ends at time $T$. The demand pattern changes twice before production is stopped, first from $g(t)$ to $g(\mu)$ and later from $g(\mu)$ to $h(t)$. The equations of the system are as follows:

$$
\begin{aligned}
& \frac{d I_{A}(t)}{d t}=K(t)-g(t)-\theta I_{A}(t), 0 \leq t \leq \mu ;\left\{I_{A}(0)=0\right\}, \\
& \frac{d I_{B}(t)}{d t}=K(t)-g(\mu)-\theta I_{B}(t) ; \mu \leq t \leq \gamma ;\left\{I_{A}(\mu)=I_{B}(\mu)\right\}, \\
& \frac{d I_{C}(t)}{d t}=K(t)-h(t)-\theta I_{C}(t), \gamma \leq t \leq t_{1} ;\left\{I_{C}(\gamma)=I_{B}(\gamma)\right\}, \\
& \frac{d I_{D}(t)}{d t}=-h(t)-\theta I_{D}(t), t_{1}<t \leq t_{2} ;\left\{I_{D}\left(t_{2}\right)=0\right\}, \\
& \frac{d I_{E}(t)}{d t}=-\beta h(t), \quad t_{2} \leq t \leq t_{3}, I_{E}\left(t_{2}\right)=0, \\
& \frac{d I_{F}(t)}{d t}=K(t)-h(t), \quad t_{3}<t \leq T, I_{F}(T)=0 .
\end{aligned}
$$

The solutions to Eq. (41) are as follows:

$$
\begin{aligned}
& I_{A}(t)=e^{-a t^{b}} \int_{0}^{t} e^{a x^{b}}(K(x)-g(x)) d x, \\
& I_{B}(t)=e^{-a t^{b}}\left(\int_{\mu}^{t} e^{a x^{b}}(K(x)-g(\mu)) d x+\int_{0}^{\mu} e^{a x^{b}}(K(x)-g(x)) d x\right), \\
& I_{C}(t)=e^{-a t^{b}}\left(\int_{\gamma}^{t} e^{a x^{b}}(K(x)-h(x)) d x+\int_{\mu}^{\gamma} e^{a x^{b}}(K(x)-g(\mu)) d x+\int_{0}^{\mu} e^{a x^{b}}(K(x)-g(x)) d x\right), \\
& I_{D}(t)=e^{-a t^{b}}\left(\int_{t}^{t_{2}} e^{a x^{b}} h(x) d x\right), \\
& I_{E}(t)=\int_{t}^{t_{2}} \beta h(x) d x, \\
& I_{F}(t)=\int_{T}^{t}(K(x)-h(x)) d x .
\end{aligned}
$$

The present worth of inventory holding cost is as follows:

$$
\begin{aligned}
& P W H C=C_{H}\left(\int_{0}^{\mu} I_{A}(t) e^{-R t} d t+\int_{\mu}^{\gamma} I_{B}(t) e^{-R t} d t+\int_{\gamma}^{t_{1}} I_{C}(t) e^{-R t} d t+\int_{t_{1}}^{t_{2}} I_{D}(t) e^{-R t} d t\right), \\
& P W S H C=-C_{S H}\left(\int_{t_{2}}^{t_{3}} I_{E}(t) e^{-R t} d t+\int_{t_{3}}^{T} I_{F}(t) e^{-R t} d t\right), \\
& P W L C=(1-\beta) C_{L}\left(\int_{t_{2}}^{t_{3}} h(t) e^{-R t} d t\right), \\
& P W P R C=C_{P}\left(\int_{0}^{\mu} K(t) e^{-R t} d t+\int_{\mu}^{\gamma} K(t) e^{-R t} d t+\int_{\gamma}^{t_{1}} K(t) e^{-R t} d t+\int_{t_{3}}^{T} K(t) e^{-R t} d t\right), \\
& P W S U C=A_{S}+A_{S} e^{-R t_{3}} .
\end{aligned}
$$

Total relevant cost is as follows: 


$$
T C_{6}\left(t_{1}, t_{2}, t_{3}\right)=P W H C+P W S H C+P W L C+P W P R C+P W S U C .
$$

As in previous cases the optimal production schedules can be obtained by minimizing $T C_{6}\left(t_{1}, t_{2}, t_{3}\right)$ subject to the constraints below.

$$
\text { I. } I_{C}\left(t_{1}\right)=I_{D}\left(t_{1}\right), \quad \text { II. } I_{E}\left(t_{3}\right)=I_{F}\left(t_{3}\right), \quad \text { III. } 0<\mu<\gamma<t_{1}<t_{2}<t_{3}<T \text {. }
$$

\section{Optimal solution procedure}

From the analysis made above, it is obvious that six (6) different strategies need be considered in order to determine the optimal production strategy to be used in a production-inventory system with deteriorating item having three-phase time varying demand pattern. The optimal strategy will be any of the cases considered above that gives the least value of total relevant cost.

To achieve this we formulate each case considered above as a constrained nonlinear optimization problem (CNLOP) and solve it using trust region methods. Trust-region methods have strong convergence properties and help to reach local minimum for any given function. According to Nocedal and Wright (1999), "the trust-region methods define a region around the current iterate within which the model is trusted to be an adequate representation of the objective function, and then choose the step to be the approximate minimizer of the model in this trust region". The CNLOP for all cases are as follows:

Case I: $\quad \mathrm{P}_{1}=\min T C_{1}\left(t_{1}, t_{2}, t_{3}\right)$ subject to $\left\{I_{A}\left(t_{1}\right)=I_{B}\left(t_{1}\right), I_{E}\left(t_{3}\right)=I_{F}\left(t_{3}\right), 0<t_{1}<\mu<\gamma<t_{2}<t_{3}<T\right\}$.

Case II: $\mathrm{P}_{2}=\min T C_{2}\left(t_{1}, t_{2}, t_{3}\right)$ subject to $\left\{I_{A}\left(t_{1}\right)=I_{B}\left(t_{1}\right), I_{E}\left(t_{3}\right)=I_{F}\left(t_{3}\right), 0<t_{1}<\mu<t_{2}<\gamma<t_{3}<T\right\}$.

Case III: $\mathrm{P}_{3}=\min T C_{3}\left(t_{1}, t_{2}, t_{3}\right)$ subject to $\left\{I_{A}\left(t_{1}\right)=I_{B}\left(t_{1}\right), I_{E}\left(t_{3}\right)=I_{F}\left(t_{3}\right), 0<t_{1}<t_{2}<\mu<\gamma<t_{3}<T\right\}$.

Case IV: $\mathrm{P}_{4}=\min T C_{4}\left(t_{1}, t_{2}, t_{3}\right)$ subject to $\left\{I_{B}\left(t_{1}\right)=I_{C}\left(t_{1}\right), I_{E}\left(t_{3}\right)=I_{F}\left(t_{3}\right), 0<\mu<t_{1}<t_{2}<\gamma<t_{3}<T\right\}$.

Case V: $\mathrm{P}_{5}=\min T C_{5}\left(t_{1}, t_{2}, t_{3}\right)$ subject to $\left\{I_{B}\left(t_{1}\right)=I_{C}\left(t_{1}\right), I_{E}\left(t_{3}\right)=I_{F}\left(t_{3}\right), 0<\mu<t_{1}<\gamma<t_{2}<t_{3}<T\right\}$.

Case VI: $\mathrm{P}_{6}=\min T C_{6}\left(t_{1}, t_{2}, t_{3}\right)$ subject to $\left\{I_{C}\left(t_{1}\right)=I_{D}\left(t_{1}\right), I_{E}\left(t_{3}\right)=I_{F}\left(t_{3}\right), 0<\mu<\gamma<t_{1}<t_{2}<t_{3}<T\right\}$.

The equation for each $T C_{i}\left(t_{1}, t_{2}, t_{3}\right)$ is obtained from the characteristics of the system as described in Section

3.1. Each of the problems above can be solved using trust region methods incorporated in the optimization toolbox of software packages like LANCELOT or MATLAB to give the optimal values of $t_{1}^{*}, t_{2}^{*}, t_{3}^{*}$ and $T C_{i}^{*}$ for each strategy. A strategy will be feasible if constraint qualification holds, otherwise it will be regarded as an infeasible strategy. The optimal cost of all feasible strategies are then compared to determine the least cost using $T C^{*}=\min \left[T C_{1}^{*}, T C_{2}^{*}, T C_{3}^{*}, T C_{4}^{*}, T C_{5}^{*}, T C_{6}^{*}\right]$, where $T C_{1}^{*}, T C_{2}^{*}, \ldots . T C_{6}^{*}$, are the optimal values obtained from the solution to problems $P_{1}, P_{2} \ldots P_{6}$, respectively.

\subsection{Alternative solution procedure}

An alternative procedure is to reduce the problem in each case to an equality constrained problem with the following Lagrange function, $L$ :

$$
L\left(t_{1}, t_{2}, t_{3}, \lambda_{1}, \lambda_{2}\right)=T C_{i}\left(t_{1}, t_{2}, t_{3}\right)+\lambda_{1} k_{1}+\lambda_{2} k_{2} \text {. }
$$

$\lambda_{1}, \lambda_{2}$ are the Lagrange multipliers while $k_{1}, k_{2}$ are obtained from the equality constraint equations .

The necessary condition for the minimization of $L\left(t_{1}, t_{2}, t_{3}, \lambda_{1}, \lambda_{2}\right)$ is as follows:

$$
\frac{\partial L}{\partial t_{1}}=0, \frac{\partial L}{\partial t_{2}}=0, \frac{\partial L}{\partial t_{3}}=0, \frac{\partial L}{\partial \lambda_{1}}=0, \frac{\partial L}{\partial \lambda_{2}}=0
$$

The resulting system of equations is then solved to obtain the optimal values of $t_{1}^{*}, t_{2}^{*}, t_{3}^{*}($ after necessary algebraic simplifications) using a robust nonlinear equation solver with the bound constraints serving as lower and upper bounds for the variables in the solver's toolbox. The corresponding value of $T C_{i}^{*}$ is obtained from the relevant equation for each case and the optimal costs of all feasible strategies are then compared to determine the least cost using $T C^{*}=\min \left[T C_{1}^{*}, T C_{2}^{*}, T C_{3}^{*}, T C_{4}^{*}, T C_{5}^{*}, T C_{6}^{*}\right]$. 


\section{Numerical examples and sensitivity analysis}

To demonstrate the application of this model for inventory situation of items with varying demand pattern and shortages over various phases in their life cycles in the market, some numerical examples are considered in this section. The parameters for the examples are as shown in Table 1 below. The procedures enumerated in the previous section are used to obtain solutions to the illustrative examples and the results obtained are shown in Tables 2- 6 .

Sensitivity analysis was performed to examine the effect of real-world data change on the model's optimal results by using the first numerical example. The values of some of the parameters were varied by $+50 \%,+25 \%,-25 \%,-50 \%$, taking one at a time while others were kept constant. The effect of these changes in values on the optimal results is presented in Table 7.

The tables of results show that Case I and Case VI give no feasible solution in all examples. This shows that Strategy I and Strategy VI are not feasible for all considered problems. In the case of Strategy I, production is stopped after a very short time and the accumulated inventory is expected to last for a longer time thereafter. This will often be impossible except under circumstances in which production rates are far higher than the demand rates. Under such cases, the accumulated inventory may be large enough to cater for demand up till towards the end of the season before being exhausted. The criteria for the feasibility of a particular production strategy can be obtained by considering the balance between the inflow and outflow of items in the production-inventory system before the onset of shortages. Since shortage begins when the inventory is exhausted, it follows that all the items produced from the beginning of the cycle to the time just before the onset of shortages (i.e. in the interval $\left.\left[0, t_{2}\right]\right)$ must be consumed by the total demand and deterioration occurs within that interval. Hence, a feasible production strategy must satisfy the criteria given in Eq. (47),

$$
\int_{0}^{t_{1}^{*}} K(t) d t=\int_{0}^{t_{2}^{*}} f(t) d t+\int_{0}^{t_{2}^{*}} \theta(t) I(t) d t
$$

The optimal value of production run time and onset of shortages lies between a maximum and a minimum value (i.e. $\left(t_{1}\right)_{\min } \leq t_{1}^{*} \leq\left(t_{1}\right)_{\max } ;\left(t_{2}\right)_{\min } \leq t_{2}^{*} \leq\left(t_{2}\right)_{\max }$ ) for each strategy. A quick way to determine an infeasible production strategy can be obtained by considering the inequality below: Maximum No. of items produced in interval $\left[0, t_{2}\right] \geq$ Minimum No. of items consumed in interval $[0$, $\left.t_{2}\right]$

$$
\int_{0}^{\left(t_{1}\right)_{\max }} K(t) d t \geq \int_{0}^{\left(t_{2}\right)_{\min }} f(t) d t+\int_{0}^{\left(t_{2}\right)_{\min }} \theta(t) I(t) d t
$$

Eq. (48) can be solved to obtain a criterion that will act as a quick check to determine whether a strategy will be infeasible for a given set of system parameters. In the case of Strategy I, Eq. (48) gives:

$$
\alpha \geq 1+\frac{\int_{\mu}^{\gamma} g(\mu) d t+\int_{0}^{\gamma} \theta(t) I(t) d t}{\int_{0}^{\mu} g(t) d t}
$$

For examples 1, 3 and 5, a necessary criterion for feasibility given by Eq. (49) is $\alpha \geq 2.7014$ and for examples 4 and example 5 it is $\alpha \geq 4.9723$ and $\alpha \geq 5.0250$, respectively. In the considered examples, however, these criteria are not met since $\alpha=1.46$. Hence, Strategy I is not feasible for all considered examples. Similar analysis can be extended to other strategies. It should be noted that Eq. (48) only gives a necessary criterion for feasibility of a strategy and not a guarantee that such strategy will be feasible. A production strategy will be feasible if its optimal schedules satisfy Eq. (47).

The significance of the above criterion is that it establishes a relation between production and demand rates for the production-inventory system. It is traditionally assumed that production rate is greater than demand rate in EPQ models but by how much production rate should be greater is not often expressed. For deteriorating items, it is not enough to just assume that production rate will be greater than demand rate since items produced are consumed by both production and deterioration. The criterion and the examples considered showed that the production rate must be sufficiently greater than demand rate in order to meet the requirements of consumption through demand and 
deterioration. The examples also show that the optimal production strategy may be different, if some of the system parameters changes. This is obvious from the results of Example 3 and Example 5 where only a change in the discount rate net of inflation $(R)$ changes the optimal production strategy from Strategy V (in Example 3) to Strategy IV (in Example 5). This underscores the importance of considering several possible strategies for every set of parameters to determine the optimal production strategy. Most production inventory models involving varying demand pattern usually consider only a single production strategy and derive the optimal results based on that strategy alone. The considered strategy may, however, not produce optimal results for some set of parameters.

\section{Table 1}

System parameters for all numerical examples

\begin{tabular}{|c|c|c|c|c|c|}
\hline \multirow[t]{2}{*}{ System Parameters } & \multicolumn{5}{|l|}{ EXAMPLES } \\
\hline & 1 & 2 & 3 & 4 & 5 \\
\hline$g(x)$ & $100+5 t$ & $300 e^{0.01 t}$ & $100+5 t$ & $300 e^{0.01 t}$ & $100+5 t$ \\
\hline$g(\mu)$ & 120 & $300 e^{0.01(1.2)}$ & 120 & $300 e^{0.01(1.2)}$ & 120 \\
\hline$h(x)$ & $220-10 t$ & $300 e^{0.01(1.2-(t-3))}$ & $220-10 t$ & $300 e^{0.01(1.2-(t-3))}$ & $220-10 t$ \\
\hline$\mu$ & 4 weeks & 1.2 months & 4 weeks & 1.2 months & 4 weeks \\
\hline$\gamma$ & 10 weeks & 3 months & 10 weeks & 3 months & 10 weeks \\
\hline$T$ & 12 weeks & 5 months & 12 weeks & 5 months & 12 weeks \\
\hline$A_{S}$ & $\$ 112.5$ & $\$ 112.5$ & $\$ 60$ & $\$ 125$ & $\$ 60$ \\
\hline$C_{P}$ & $\$ 6$ & $\$ 6$ & $\$ 4$ & $\$ 10$ & $\$ 4$ \\
\hline$C_{H}$ & $\$ 0.3$ & $\$ 0.3$ & $\$ 0.2$ & $\$ 0.7$ & $\$ 0.2$ \\
\hline$C_{L}$ & $\$ 10$ & $\$ 10$ & $\$ 6$ & $\$ 15$ & $\$ 6$ \\
\hline$C_{S H}$ & $\$ 7$ & $\$ 7$ & $\$ 3.5$ & $\$ 12$ & $\$ 3.5$ \\
\hline$a$ & 0.001 & 0.001 & 0.001 & 0.005 & 0.001 \\
\hline$b$ & 2 & 2 & 2 & 2 & 2 \\
\hline$R$ & 0.08 & 0.08 & 0.08 & 0.08 & 0.15 \\
\hline$\beta$ & & 0.8 & 0.8 & 0.8 & 0.8 \\
\hline$\alpha$ & $175 / 120$ & $175 / 120$ & $175 / 120$ & $175 / 120$ & $175 / 120$ \\
\hline
\end{tabular}

\section{Table 2}

Result of numerical example 1

\begin{tabular}{|c|c|c|c|c|c|c|c|c|}
\hline & \multicolumn{4}{|c|}{ Trust Region Method } & \multicolumn{4}{|c|}{ Lagrange Method } \\
\hline & $t_{1}^{*}$ & $t_{2}^{*}$ & $t_{3}^{*}$ & $T C_{i}^{*}$ & $t_{1}^{*}$ & $t_{2}^{*}$ & $t_{3}^{*}$ & $T C_{i}^{*}$ \\
\hline Case I & infeasible & & & & \multicolumn{4}{|c|}{ Infeasible Solution } \\
\hline Case II & 4.0000 & 5.6511 & 10.0000 & 8442.2 & \multicolumn{4}{|c|}{ Infeasible Solution } \\
\hline Case III & 2. 8260 & 4.0000 & 10.0000 & 10939 & 3.4133 & 4.0000 & 10.0000 & 11408 \\
\hline Case IV & 7.0728 & 10.0000 & 10.6875 & 6609.7 & 7.3258 & 10.0000 & 10.5929 & 6689.1 \\
\hline Case V & 7.3884 & 10.4467 & 10.9871 & 6597.0 & 7.8387 & 10.7700 & 11.1174 & 6759.4 \\
\hline Case VI & & \multicolumn{7}{|c|}{ Infeasible Solution } \\
\hline
\end{tabular}

\section{Table 3}

Result of numerical example 2

\begin{tabular}{|c|c|c|c|c|c|c|c|c|}
\hline & \multicolumn{4}{|c|}{ Trust Region Method } & \multicolumn{4}{|c|}{ Lagrange Method } \\
\hline & $t_{1}^{*}$ & $t_{2}^{*}$ & $t_{3}^{*}$ & $T C_{i}^{*}$ & $t_{1}^{*}$ & $t_{2}^{*}$ & $t_{3}^{*}$ & $T C_{i}^{*}$ \\
\hline Case I & infeasible & & & & \multicolumn{4}{|c|}{ Infeasible Solution } \\
\hline Case II & 1.2 & 1.4082 & 2.9744 & 53301 & \multicolumn{4}{|c|}{ Infeasible Solution } \\
\hline Case III & 1.0318 & 1.2000 & 3.0000 & 56258 & 1.1943 & 1.2000 & 3.0000 & 59901 \\
\hline Case IV & 2.2936 & 3.0000 & 3.2212 & 50048 & 2.3165 & 3.0000 & 3.2138 & 50668.9 \\
\hline Case V & 2.5967 & 4.0573 & 4.2421 & 49112 & 2.6291 & 4.7948 & 5.0000 & 49118 \\
\hline Case VI & & & & & \multicolumn{4}{|c|}{ Infeasible Solution } \\
\hline
\end{tabular}

Strategy II gave lower total inventory cost compared with Strategy III in all numerical examples. This can be attributed to the fact that Strategy III is always associated with longer stock-out period compared with Strategy II. This brings about a comparably higher stock-out and lost cost. 
The sensitivity analysis shows that the optimal production quantity generated by the model is moderately sensitive to changes in production rate $(\alpha)$, deterioration rate $(b)$ and demand trend $(\gamma)$. It however has low sensitivity to other system parameters. The production schedules, on the other hand, is highly sensitive to both production rate $(\alpha)$, and demand trend $(\gamma)$ but moderately sensitive to discount rate net of inflation $(R)$, shortage cost $\left(C_{S H}\right)$ and production cost $\left(C_{P}\right)$. Its sensitivity to other parameters is relatively low.

\section{Table 4}

Result of numerical example 3

\begin{tabular}{|c|c|c|c|c|c|c|c|c|}
\hline & \multicolumn{4}{|c|}{ Trust Region Method } & \multicolumn{4}{|c|}{ Lagrange Method } \\
\hline & $t_{1}^{*}$ & $t_{2}^{*}$ & $t_{3}^{*}$ & $T C_{i}^{*}$ & $t_{1}^{*}$ & $t_{2}^{*}$ & $t_{3}^{*}$ & $T C_{i}^{*}$ \\
\hline Case I & \multicolumn{4}{|c|}{ infeasible } & \multicolumn{4}{|c|}{ Infeasible Solution } \\
\hline Case II & 4.0000 & 5.6511 & 10.0000 & 4984.1 & \multicolumn{4}{|c|}{ Infeasible Solution } \\
\hline Case III & 2. 8260 & 4.0000 & 10.0000 & 6096.6 & 3.1413 & 4.0000 & 10.0000 & 6264.4 \\
\hline Case IV & 6.9957 & 9.8926 & 10.6153 & 4348.9 & 7.1989 & 10.0000 & 10.6427 & 4409.5 \\
\hline Case V & 7.0728 & 10.0000 & 10.6875 & 4348.1 & 7.2685 & 10.1000 & 10.7108 & 4407.8 \\
\hline Case VI & & & & & \multicolumn{4}{|c|}{ Infeasible Solution } \\
\hline
\end{tabular}

Table 5

Result of numerical example 4

\begin{tabular}{|c|c|c|c|c|c|c|c|c|}
\hline & \multicolumn{4}{|c|}{ Trust Region Method } & \multicolumn{4}{|c|}{ Lagrange Method } \\
\hline & $t_{1}^{*}$ & $t_{2}^{*}$ & $t_{3}^{*}$ & $T C_{i}^{*}$ & $t_{1}^{*}$ & $t_{2}^{*}$ & $t_{3}^{*}$ & $T C_{i}^{*}$ \\
\hline Case I & \multicolumn{4}{|c|}{ Infeasible Solution } & \multicolumn{4}{|c|}{ Infeasible Solution } \\
\hline Case II & 1.2 & 1.4074 & 2.9745 & 88357 & \multicolumn{4}{|c|}{ Infeasible Solution } \\
\hline Case III & 1.0322 & 1.2 & 3.0000 & 93291 & 1.2 & 1.2000 & 3.0000 & 99610 \\
\hline Case IV & 2.3023 & 3.0000 & 3.2212 & 83991 & 2.3655 & 3.0000 & 3.5148 & 84361 \\
\hline Case V & 2.5702 & 3.7212 & 3.9259 & 82939 & 2.6353 & 4.4388 & 5.0000 & 82885 \\
\hline Case VI & \multicolumn{4}{|c|}{ Infeasible Solution } & \multicolumn{4}{|c|}{ Infeasible Solution } \\
\hline
\end{tabular}

The optimal value of total cost generated by the model is highly sensitive to changes in production rate $(\alpha)$, discount rate net of inflation $(R)$, and production cost $\left(C_{P}\right)$ but moderately sensitive to demand trend $(\gamma)$ and inventory holding cost $\left(C_{H}\right)$. It also becomes moderately sensitive to increase in deterioration rate while it is less sensitive to decrease in the same rate. Some parameters have a limit to which they can be varied otherwise they become inconsistent with system assumptions. Table 7 shows infeasible result for such cases.

\section{Table 6}

Result of numerical example 5

\begin{tabular}{|c|c|c|c|c|c|c|c|c|}
\hline & \multicolumn{4}{|c|}{ Trust Region Method } & \multicolumn{4}{|c|}{ Lagrange Method } \\
\hline & $t_{1}^{*}$ & $t_{2}^{*}$ & $t_{3}^{*}$ & $T C_{i}^{*}$ & $t_{1}^{*}$ & $t_{2}^{*}$ & $t_{3}^{*}$ & $T C_{i}^{*}$ \\
\hline Case I & \multicolumn{4}{|c|}{ Infeasible Solution } & \multicolumn{4}{|c|}{ Infeasible Solution } \\
\hline Case II & 4.0000 & 5.6511 & 10.0000 & 3462.1 & \multicolumn{4}{|c|}{ Infeasible Solution } \\
\hline Case III & 2. 8260 & 4.0000 & 10.0000 & 4039.4 & 3.3517 & 4.0000 & 10.0000 & 4265.1 \\
\hline Case IV & 6.1899 & 8.7646 & 9.8829 & 3274.6 & 7.2056 & 10.0000 & 10.6516 & 3380 \\
\hline Case V & 7.0728 & 10.0000 & 10.6875 & 3313.1 & 7.2056 & 10.0000 & 10.6516 & 3337.4 \\
\hline Case VI & \multicolumn{4}{|c|}{ Infeasible Solution } & \multicolumn{4}{|c|}{ Infeasible Solution } \\
\hline
\end{tabular}

Optimal production strategy: Strategy IV, $T C^{*}=\$ 3274.6 ; Q^{*}=1366.3$ units

It is important to note the change in optimal production strategy with changes in the production rate parameter as shown by the sensitivity analysis. Table 7 shows that the optimal production strategy changes from Strategy V to Strategy VI when the production rate is reduced. This indicates that as production rate reduces, the production schedules also need to be increased for optimal result. Production Strategy V produces feasible but not optimal result in this case. 
Table 7

Sensitivity analysis based on Example 1

\begin{tabular}{|c|c|c|c|c|c|c|c|}
\hline & $\%$ Change & Strategy & $t_{1}^{*}$ & $t_{2}^{*}$ & $t_{3}^{*}$ & $T C^{*}$ & $Q^{*}$ \\
\hline \multirow{4}{*}{$\beta$} & -25 & Strategy V & 0.6 & 0.62 & 1.31 & 0.26 & -1.09 \\
\hline & -50 & Strategy V & 1.63 & 1.67 & 3.17 & 0.61 & -2.45 \\
\hline & 25 & Strategy V & -0.41 & -0.41 & -0.97 & -0.19 & 0.86 \\
\hline & 50 & & infeasible & & & & \\
\hline \multirow{4}{*}{$R$} & -25 & Strategy V & 2.52 & 2.59 & 1.64 & 8.89 & 0.28 \\
\hline & -50 & Strategy V & 4.85 & 5.04 & 3.17 & 18.87 & 0.55 \\
\hline & 25 & Strategy V & -2.73 & -2.74 & -1.75 & -7.94 & -0.3 \\
\hline & 50 & Strategy V & -4.27 & -4.28 & -2.73 & -15.02 & -0.46 \\
\hline \multirow{4}{*}{$C_{S H}$} & -25 & Strategy V & -4.27 & -4.28 & -2.73 & -0.54 & -0.46 \\
\hline & -50 & Strategy V & -4.27 & -4.28 & -2.73 & -1.25 & -0.46 \\
\hline & 25 & Strategy V & 2.7 & 2.78 & 1.76 & 0.33 & 0.3 \\
\hline & 50 & Strategy V & 4.51 & 5 & 2.95 & 0.55 & 0.51 \\
\hline \multirow{4}{*}{$C_{L}$} & -25 & Strategy V & -0.9 & -0.91 & -0.58 & -0.2 & -0.09 \\
\hline & -50 & Strategy V & -1.83 & -1.85 & -1.17 & -0.42 & -0.2 \\
\hline & 25 & Strategy V & -0.88 & -0.9 & 0.57 & 0.19 & 0.1 \\
\hline & 50 & Strategy V & 1.74 & 1.78 & 1.13 & 0.37 & 0.19 \\
\hline \multirow{4}{*}{$C_{P}$} & -25 & Strategy V & 3.07 & 3.16 & 0.71 & -22.49 & 0.35 \\
\hline & -50 & Strategy V & 6.05 & 6.33 & 3.98 & -45.15 & 0.68 \\
\hline & 25 & Strategy V & -3.15 & -3.17 & -2.02 & 22.32 & -0.34 \\
\hline & 50 & Strategy V & -4.27 & -4.28 & -2.73 & 44.51 & -0.46 \\
\hline \multirow{4}{*}{$C_{H}$} & -25 & Strategy V & 1.21 & 1.24 & 0.79 & -1.39 & 0.14 \\
\hline & -50 & Strategy V & 2.43 & 2.5 & 1.58 & -2.82 & 0.27 \\
\hline & 25 & Strategy V & -1.2 & -1.22 & -0.78 & 1.37 & -0.12 \\
\hline & 50 & Strategy V & -2.4 & -2.42 & -1.54 & 2.71 & -0.26 \\
\hline \multirow{4}{*}{$a$} & -25 & Strategy V & -0.12 & 0.3 & 0.19 & -0.25 & -0.35 \\
\hline & -50 & Strategy V & -0.22 & 0.63 & 0.4 & -0.51 & -0.71 \\
\hline & 25 & Strategy V & 0.12 & -0.28 & -0.18 & 0.24 & 0.34 \\
\hline & 50 & Strategy V & 0.25 & -0.27 & -0.34 & 0.47 & 0.67 \\
\hline \multirow{4}{*}{$b$} & -25 & Strategy V & -0.1 & 1.03 & 0.65 & -0.74 & -1.01 \\
\hline & -50 & Strategy V & -0.34 & 1.31 & 0.83 & -0.98 & -1.36 \\
\hline & 25 & Strategy V & 0.31 & -2.72 & -1.73 & 1.93 & 2.51 \\
\hline & 50 & Strategy V & 5.12 & -4.28 & -2.73 & 5.58 & 8.28 \\
\hline \multirow{4}{*}{$\mu$} & -25 & Strategy V & -0.12 & -0.03 & -0.02 & 0.21 & 0.18 \\
\hline & -50 & Strategy V & -0.47 & -0.14 & -0.09 & 0.92 & 0.72 \\
\hline & 25 & Strategy V & -0.12 & -0.03 & -0.02 & 0.18 & 0.18 \\
\hline & 50 & Strategy V & -0.48 & -0.14 & -0.09 & 0.67 & 0.71 \\
\hline \multirow{4}{*}{$\gamma$} & -25 & Strategy V & 3.39 & 0.96 & 0.61 & 1.64 & 2.38 \\
\hline & -50 & Strategy V & 13.03 & 3.65 & 2.3 & 5.57 & 9.24 \\
\hline & 10 & Strategy V & 5.49 & 5.3 & 3.33 & 0.52 & 0.95 \\
\hline & 50 & & infeasible & & & & \\
\hline \multirow{4}{*}{$\alpha$} & -25 & Strategy VI & 35.35 & 4.12 & 6.56 & -14.04 & -6.38 \\
\hline & -50 & & infeasible & & & & \\
\hline & 25 & Strategy V & -19.92 & -1.62 & 1.18 & 8.47 & -0.03 \\
\hline & 50 & Strategy V & -33.04 & -2.7 & 2.15 & 14.4 & -0.16 \\
\hline
\end{tabular}

\section{Conclusions}

This paper has presented production-inventory models for deteriorating items having varying demand patterns with Weibull-distribution deterioration and partial backlogging under the effect of inflation and time value of money. The models involved different production strategies that can be adopted for producing deteriorating items with increasing-steady-decreasing demand pattern. A general ramptype demand function that allows for three-phase variation in demand pattern was used to represent the demand while the discounted cash flow approach and trust region optimization methods were used to obtain the optimal production strategy. The models obtained the optimal values of initial production run time, onset of shortages, production recommencement time, and total production quantity that minimizes total relevant costs of production and inventory for any given set of system parameters. The examples and sensitivity analysis also showed that the optimal production strategy may vary with changes in system parameters. The implication of this is that, contrary to usual 
practice, it is important to consider several possible production strategies when dealing with items having varying demand patterns in order to determine the optimal production strategy for a given set of system parameter. This study can be extended by considering variable production cost, imperfect production process or an integrated system involving co-operation between manufacturers and retailers. Another possible area for future research is the consideration of multi-product system with variable lead time.

\section{Acknowledgment}

The authors would like to thank the anonymous referees for their valuable comments and suggestions for the improvement of this paper.

\section{References}

Abad, P. L. (2003). Optimal pricing and lot-sizing under conditions of perishability, finite production and partial backordering and lost sale. European Journal of Operational Research, 144, 677-685.

Abdul, I. \& Murata, A. (2011). An inventory model for deteriorating items with varying demand pattern and unknown time horizon. International Journal of Industrial Engineering Computations, 2, 61-86.

Alfares, H. K., Khursheed, S. N. \& Noman, S. M. (2005). Integrating quality and maintenance decisions in a production inventory model for deteriorating items. International Journal of Production Research, 43 (5), 899-911.

Balkhi, Z. T. (2001). On a finite horizon production lot size inventory model for deteriorating items: An optimal solution. European Journal of Operational Research, 132, 210-223.

Chern, M-S., Yang, H-L., Teng, J-T. \& Papachristos, S. (2008). Partial backlogging inventory lot-size models for deteriorating items with fluctuating demand under inflation. European Journal of Operational Research, 191, 127-141.

Chang, H-J., Hung, C-H. \& Dye, C-Y. (2002). A finite horizon inventory model with deterioration and timevalue of money under the conditions of permissible delay in payments. International Journal of Systems Science, 33(2), 141-151.

Chang, H-J., Teng, J-T, Ouyang, L-Y. \& Dye, C-Y. (2006). Retailer's optimal pricing and lot-sizing policies for deteriorating items with partial backlogging. European Journal of Operational Research, 168, 51-64.

Cheng, M. \& Wang, G. (2009). A note on the inventory model for deteriorating items with trapezoidal type demand rate. Computers \& Industrial Engineering, 56, 1296-1300.

Chung, K-J. \& Tsai, S-F. (2001). Inventory systems for deteriorating items with shortages and a linear trend in demand taking account of time value. Computers \& Operations Research, 28, 915-934.

Dey, J. K., Mondal, S. K. \& Maiti, M. (2008). Two storage inventory problem with dynamic demand and interval valued lead-time over finite time horizon under inflation and time-value of money. European Journal of Operational Research, 185, 170-194.

Ghare, P.M. \& Schrader, G.F. (1963). A model for exponential decaying inventory. Journal of Industrial Engineering, 14, 238-243.

Goyal, S. K. \& Giri, B. C. (2003). The production-inventory problem of a product with time varying demand, production and deterioration rates. European Journal of Operational Research, 147, 549-557.

Hariga, M. A. (1995). An EOQ model for deteriorating items with shortages and time-varying demand. Journal of the Operational Research Society, 46, 398-404.

Hedjar, R., Bounkhel, M. \& Tadj, L. (2004). Predictive control of periodic-review of production inventory systems with deteriorating items. Sociedad de Estadistica e Investigacion Operativa Top, 12(1), 193-208.

Hou, K-L. (2006). An inventory model for deteriorating items with stock-dependent consumption rate and shortages under inflation and time discounting. European Journal of Operational Research, 168, 463-474.

Hill, R. M. (1995). Inventory model for increasing demand followed by level demand. Journal of the Operational Research Society, 46, 1250-1259.

Jaggi, C. K., Goel, S. K. \& Mittal, M. (2011). Economic order quantity model for deteriorating items with imperfect quality and permissible delay on payment. International Journal of Industrial Engineering Computations, 2, pp. 237-248.

Jolai, F., Tavakkoli-Moghaddam, R., Rabbani, M. \& Sadoughian, M. R. (2006). An economic production lot size model with deteriorating items, stock-dependent demand, inflation, and partial backlogging. Applied Mathematics and Computation, 181, 380-389.

Lin, Y. \& Lin, C. (2006). Purchasing model for deteriorating items with time-varying demand under inflation and time discounting. International Journal of Advance Manufacturing Technology, 27, 816-823. 
Lo, S-T., Wee, H. W. \& Huang, W-C. (2007). An integrated production-inventory model with imperfect production processes and Weibull distribution deterioration under inflation. International Journal of Production Economics, 106, 248-260.

Mahata, G. C. \& Goswami, A. (2009). A fuzzy replenishment policy for deteriorating items with ramp-type demand rate under inflation. International Journal of Operational Research, 5, 328 - 348.

Maity, K. \& Maiti, M (2005). Numerical approach of multi-objective optimal control problem in imprecise environment. Fuzzy Optimization and Decision Making, 4, 313-330.

Mandal, B. \& Pal, A. K. (1998). Order level inventory system with ramp-type demand rate for deteriorating items. Journal of Interdisciplinary Mathematics, 1, 49-66.

Manna, S. K. \& Chaudhuri, K. S. (2006). An EOQ model with ramp-type demand rate, time dependent deterioration rate, unit production cost and shortages. European Journal of Operational Research, 171, 557-566.

Manna, S. K. \& Chiang, C. (2010). Economic production quantity models for deteriorating items with ramptype demand. International Journal of Operational Research, 7, 429-444.

Misra, R. B. (1975). Optimum production lot size model for a system with deteriorating inventory. International Journal of Production Research, 13, 495-505.

Moon, I., Giri, B. C. \& Ko, B. (2005). Economic order quantity models for ameliorating/deteriorating items under inflation and time discounting. European Journal of Operational Research, 162, 773-785.

Nahmias, S. (1982). Perishable inventory theory: A review. Operations Research, 30, 680-708.

Ouyang, L-H., Teng, J-T. \& Chen, L-H. (2006). Optimal ordering policy for deteriorating items with partial backlogging under permissible delay in payments. Journal of Global Optimization, 34, 245-271.

Papachristos, S. \& Skouri, K. (2000). An optimal replenishment policy for deteriorating items with timevarying demand and partial (exponential type) backlogging. Operations Research Letters, 27, 175-184.

Pal, S., Maiti, M.K. \& Maiti, M. (2009). An EPQ model with price discounted promotional demand in an imprecise planning horizon via Genetic Algorithm, Computers and Industrial Engineering, 57, 181-187.

Panda, S., Saha, S. \& Basu, M. (2009a). Optimal production stopping time for perishable products with ramptype quadratic demand dependent production and setup cost, Central European Journal of Operational Research, 17, 381-396.

Panda S., Senapati, S. \& Basu, M. (2009b). A single cycle perishable inventory model with time dependent quadratic ramp-type demand and partial backlogging. International Journal of Operational Research, 5, $110-129$.

Raafat, F. (1991). Survey of literature on continuously deteriorating inventory models. Journal of the Operational Research Society, 42, 27-37.

Shah, N. H. (2006). Inventory model for deteriorating items and time value of money for a finite time horizon under the permissible delay in payments. International Journal of Systems Science, 37(1), 9-15.

Sridevi, G., Nirupama Devi, K. \& Srinivasa Rao, K. (2010). Inventory model for deteriorating items with Weibull rate of replenishment and selling price dependent demand. International Journal of Operational Research, 9, $329-349$.

Taft, E.W. (1918). The most economical production lot. The Iron Age, 101, 1410-1412.

Taleizadeh, A. A., Wee, H. M. \& Sadjadi, S. J. (2010). Multi-product production quantity model with repair failure and partial backordering. Computers \& Industrial Engineering, 59, 45-54.

Urban, T.L. (2005). Inventory models with inventory-level-dependent demand: A comprehensive review and unifying theory. European Journal of Operational Research, 162, 792-804.

Wee, H. M. \& Law, S-T. (2001). Replenishment and pricing policy for deteriorating items taking into account the time-value of money. International Journal of Production Economics, 71, 213-220.

$\mathrm{Wu}, \mathrm{K}-\mathrm{S}$. (2001). An EOQ inventory model for items with Weibull distribution deterioration, ramp-type demand rate and partial backlogging. Production Planning and Control, 12(8), 787-793.

Yang, P. \& Wee, H. (2003). An integrated multi-lot-size production inventory model for deteriorating item. Computer \& Operations Research, 30(5): 671- 682.

Yang, H-L. (2005). A comparison among various partial backlogging inventory lot-size models for deteriorating items on the basis of maximum profit. International Journal of Production Economics, 96, $119-128$.

Yu, J. C. P. (2007). A joint economic production lot size model for a deteriorating item with decreasing warehouse rental overtime. In: O. Gervasi \& M. Gavrilova (Eds.). Computational Science and Its Application, Springer, Berlin, LNCS 4705, 8. 